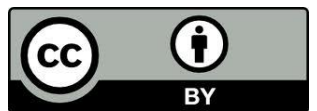

\title{
RECONHECIMENTO E ORGANIZAÇÃO DAS RELIGIÕES AFRO- BRASILEIRAS NUMA CIDADE DE COLONIZAÇÃO GERMÂNICA
}

\author{
Recognition and Organization of Afro-Brazilian Religions in Settlement City Germanic
}

\author{
Gerson Machado \\ Doutor em História pela UFSC, 2012. \\ Especialista Cultural/Educador - FCJ/MASJ. \\ e-mail: gerson_machado@uol.com.br
}

RESUMO: Neste artigo apresento reflexões sobre a construção de um saber-poder a respeito das religiões afro-brasileiras em Joinville/SC, cidade que ocupa papel de destaque no processo de ocupação europeia no Sul do Brasil, mas que acolheu outras identidades em seu território, desde meados do século XIX. É uma reflexão historiográfica que problematiza a teia constituidora das dizibilidades inerentes ao estabelecimento dessas religiões no cenário da cidade, nas décadas finais do século $\mathrm{XX}$, apontando para estratégias de consolidação dos grupos e para as críticas às fontes utilizadas na construção do saber historiográfico. Neste cenário, as fontes orais exigem do historiador uma sensibilidade específica para valorar e sistematizar narrativas, aparentemente desconexas, as quais, associadas às outras formas de enunciação, conferem sentidos à realidade, distintos daqueles sustentados pelo "status quo". Diante disso, espaço, tempo e narrativa são fenômenos de uma trama em que essas agremiações religiosas a um só tempo reivindicam o direito ao pertencimento à cidade ao mesmo tempo em que reafirmam que a realidade social é consolidada na e pelas diferenças.

Palavras chave: Memória, Identidade, Religiões afro-brasileiras, Candomblé, Mercado Religioso.

ABSTRACT: This article presents reflections in construction of a power-knowledge about the AfricanBrazilian religions in Joinville / SC, a city that occupies a prominent role in the European process of occupation in southern Brazil, but welcomed other identities in their territory, provided mid-nineteenth century. It is a historiographical analysis that questions constitutor of web of sayable inherent of establishment of these religions in the city scene, in the final decades of the twentieth century, pointing to consolidation strategies of groups and criticism of sources used in the construction of knowledge historiographical. In this scenario, the oral sources require historian a specific sensitivity to assess and systematize narratives, seemingly unconnected, which, associated with other forms of enunciation, gives way to reality, distinct from those supported by the "status quo." Thus, space, time and narrative are phenomena of a plot in which these religious associations at the same time claim the right to belonging to the city while reaffirming that social reality is consolidated in and differencest.

Keywords: Memory, Identity, African-Brazilian religions, Candomblé, Religious Market. 
Neste trabalho apresento reflexões sobre as formas pelas quais as religiões de matriz afro-brasileiras se estabelecem numa cidade catarinense marcada pela industrialização e pelo mito fundador europeu vinculado aos europeus setentrionais. Joinville/SC é o cenário sobre o qual me detenho, procurando entender como a cidade acolhe essas manifestações religiosas. Sendo uma cidade profundamente marcada pelo ethos do trabalho e pelo mito do empreendedorismo alemão, a presença religiosa afrobrasileira neste cenário se apresenta como um dado inusitado aos olhares pouco familiarizados às idiossincrasias da cidade, tendo em vista o reconhecimento da alteridade e o auto reconhecimento dos seus membros. O termo religiões afro-brasileiras alcança um universo bastante amplo de denominações religiosas que possuem, por um lado, uma matriz proveniente do continente africano e, por outro, elementos das diversas religiões e religiosidades que se desenvolveram no território brasileiro e que serviram de amálgama, em trajetórias que dialogam de perto com as configurações de cada período.

Para o desenvolvimento de uma pesquisa num cenário tão complexo, foi importante calibrar o olhar procurando indícios que marcaram o desenvolvimento dessa prática religiosa no tempo, procurando entender: qual o trânsito dos fiéis nos espaços da cidade, ou, como eles incluem a cidade na sua prática religiosa? Como os elementos constituintes do Candomblé (hierarquia, segredo, doutrina e perpetuação) chegam aos ilês axés da cidade? De que forma Joinville se insere na logística de expansão dessas religiões no Brasil? Como os sinais distintivos dessas religiões são negociados no mercado religioso da cidade?

Todavia, o cenário joinvilense possui outras variantes que, possivelmente, apimentam essa interpretação. Dentre eles, se destaca a narrativa histórica consagrada pela historiografia oficial que se baseia nos princípios do Deutschtum. Esta apregoa ao imigrante dessa etnia o papel de empreendedor, de herói, de desbravador. A crença é a de que, ao aportar em terras brasileiras, esse imigrante trazia todas essas qualidades, as quais, muitos acreditam, seriam inatas a todos os germânicos. ${ }^{1}$ Todos sabem que essa crença se fundamenta, também, em teorias de cunho racistas, que estiveram muito em voga no Brasil em meado do século XIX até meados do século XX. ${ }^{2}$ Sandra Pesavento

${ }^{1}$ SEYFERTH, 1974; GRUNER, 2003 e MACHADO, 2015.

${ }^{2}$ SCHWARCZ, 1993. 
analisa o caso de Porto Alegre onde, no fim do século XIX, se consolida uma elite branca ilustrada, com ideais de modernização em todos os níveis da sociedade local e nacional, inspirados no ideário positivista. Diante disso, essa autora questiona: "neste Rio Grande republicano não havia lugar para crendices, superstições, bruxarias, batuque, feitiços... ou haveria?" 3 Como resposta Pesavento evidencia várias práticas e personagens que continuaram a existir mesmo em detrimento de toda a campanha estabelecida, desde então.

Aqui é preciso contrapor o caso de Joinville que, diferentemente da capital gaúcha, não possui uma história assentada nos princípios coloniais escravistas. $\mathrm{Na}$ verdade a Colônia Dona Francisca nasce como um espaço "redimido" dentro do cenário nacional já que, a grosso modo, sua fundação se situa no processo de modernização do estado/império brasileiro, marcado pelo esforço da substituição da mão de obra escrava pelo imigrante-colonizador-trabalhador-assalariado. É importante ressaltar que uma das condições que o imigrante tinha de respeitar na referida colônia era a impossibilidade de possuir escravos. Contudo, essa determinação não o impedia de utilizar essa força de trabalho, já que é sabido que, no entorno da colônia, havia vários sesmeiros, proprietários de escravos, sendo a contratação desse tipo de mão de obra algo plenamente plausível, tema que carece de pesquisa. ${ }^{4}$

Um fenômeno mais recente fornece mais energia ao complexo sistema de estruturação das religiões afro-brasileira na "Manchester Catarinense". Aqui estou me referindo ao processo de crescimento industrial e populacional, intensificado a partir da década de 1960, o qual, entre outros aspectos, provoca também uma alteração nas práticas religiosas de matriz afro-brasileira. Conforme relatos a cidade, até então, possuía cultos dessa matriz que se manifestavam, a princípio, de forma aleatória e, em alguns casos, em casas de particulares e/ou terreiros dedicados a este fim. Diante disso, esse cenário passou por uma profunda alteração, em virtude de novos elementos que passaram a compor a cidade, como: o aumento populacional, a diversidade de rituais e de religiões e a consequente negociação dos sinais diacríticos, com os quais os grupos religiosos passaram a se identificar. Se até cerca de 1980 as práticas religiosas afrobrasileiras estavam mais próximas do modelo umbandista, a partir de então o cenário religioso da cidade passa a ser ocupado, também, pelos candomblecistas, com a 
instalação/fundamentação de um ilê axé na cidade. Conforme relatos, frequentavam esse espaço desde adeptos assumidos até personalidades públicas do mundo políticoeconômico-social de Joinville e região, estes, porém, de forma discreta. Essa situação está em consonância com uma das características do período que é a universalização dessas religiões, afrouxando as cercas que as instituíam como um dado exclusivo da etnia negra. ${ }^{5}$

Vários indícios apontam para uma oferta relativamente generosa de serviços religiosos na cidade. Eles evidenciam além de um mercado consumidor uma ampla rede constituidora de uma comunidade de sentidos que além de ocupar as páginas dos classificados dos jornais diários, também, tem serviços ofertados e divulgados por um dos marketings mais infalíveis que existe que o sistema "boca-a boca". Se há o crente este o é identificado à medida em que testemunha a eficácia do outro, ou como diria Jacques Derrida “ Não há religio sem sacramentum, sem aliança e promessa de testemunhar em verdade da verdade, isto é, de dizer a verdade." 6

Também, podemos perceber que esse mercado oscila á medida que a grande mídia transforma em produto cultural, disponível ao consumo, o tema do esoterismo, como bem demonstra a reportagem intitulada "O esotérico na televisão". ${ }^{7}$ Os anúncios da década de 1980, especialmente, informam ao mercado religioso a oferta de outros serviços espirituais além do que costumeiramente vinha sendo ofertado na cidade. É neste período que os serviços do Candomblé passam a constituir um discurso religioso na cidade, dado ao consumo. Dito de outra forma, pela imprensa é possível acompanhar a emergência de uma nova dizibilidade em termos de religião que passa a compor a "fisiognomia" da cidade.

Essa emergência fica evidente ao percebemos que Iyalorixás e babalorixás ofertam, claramente, seus serviços, procurando diferenciá-lo em relação aos demais, como é o caso da do jogo de búzios, um oráculo comumente utilizado nos Candomblés. Outros anúncios simplesmente ofertam os serviços, indicando uma forma de contato, mantendo incógnito o prestador do serviço. Silas Guerreiro comenta: "A oferta de práticas divinatórias em praças públicas não causa estranheza na paisagem das grandes cidades, fazendo parte do cotidiano de um amplo contingente de pessoas. É preciso

\footnotetext{
${ }^{5}$ PRANDI, 2003, PIERUCCI, 2006.

${ }^{6}$ DERRIDA, 2000, p. 45.

${ }^{7}$ A NOTÍ́CIA, 03.11.1987, s.p.
} 
perceber de que maneira os jogos divinatórios mantém uma aura misteriosa e oculta ao mesmo tempo em que se abrem a uma exposição pública e à oferta de seus produtos como numa feira comercial." 8 Os itens 1,2 e 5 da Figura 01 mostra as estratégia das ofertas em atender além das questões pessoais assuntos ligados ao mundo dos negócios empresariais, comerciais e industriais, especialmente, prometendo, conforme o item 1, orientações para "problemas comerciais, industriais e assuntos particulares", numa clara consonância com o espírito da cidade, apontado anteriormente. Os anúncios revelam, também, que alguns locais estavam situados no centro da cidade em residências, como é o caso do item 3, na qual Dona Alice oferta consultas espirituais com cartas, búzios e tarô, na Rua Dona Francisca, nº 490, na área central de Joinville ${ }^{9}$. Neste endereço ela atendeu até o ano de 2010. O item 1, também ofertava serviços na Rua Lages, 978, num bairro central da cidade, América, há umas 5 quadras de distância da casa de D. Alice.

De outra maneira, dos anúncios selecionados, gostaria de destacar o item 4, da figura 1, que anuncia a transferência do local de atendimento da "dona Marli da rua Guarujá", no Bairro Itaum, quando esta passa a atender na rua Suburbana, 401, no Bairro Fátima, sem informar um telefone para contato. Isso revela, sobretudo, a existência de um ilê axé estruturado, sendo que à medida que as pessoas necessitassem dos serviços poderiam comparecer no endereço indicado. Também, gostaria de destacar o tom familiar com que "A dona Marli da rua Guarujá" é apresentada, revelando uma certa popularidade desta sacerdotisa. Desconfio, inclusive, que tal anúncio possa ter sido encomendado por algum filho espiritual da Iyalorixá, ou ainda, algum cliente, satisfeito, grato e dando testemunho de sua eficácia.

\footnotetext{
${ }^{8}$ GUERREIRO, 2009, p. 254

${ }^{9}$ Dona Alice atendeu por mais de trinta anos na Rua dona Francisca, 490, Centro. Atualmente, não atende mais neste endereço, pois teve de mudar em virtude dos constantes alagamentos que o imóvel vem sofrendo. É Natural de São Paulo, não possui casa de santo estruturada mas atende no seu domicílio inúmeros consulentes.
} 
Figura 01 - "Pot-pourri” de serviços espirituais ofertados em classificados de jornal

1

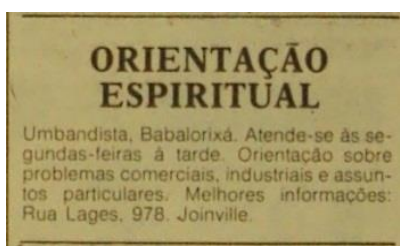

3

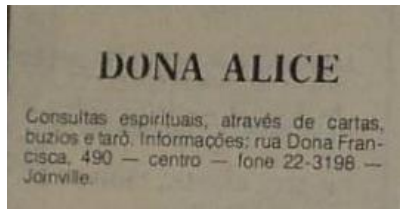

5

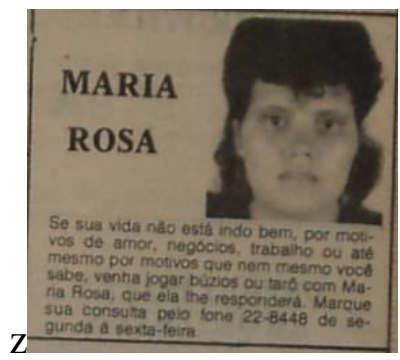

$2(*)$

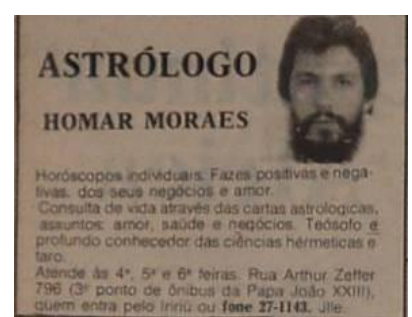

4

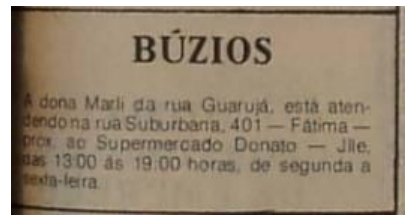

$6(*)$

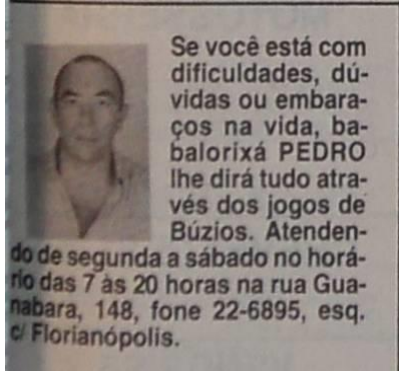

Notas:

1- Jornal A Notícia. Classificados, 30 ago. 1980, p.17.

2- Jornal A Notícia. Classificados, 06 dez. 1985, p.16.

3- Jornal A Notícia. Classificados, 02 set. 1987, p. 18

4- Jornal A Notícia. Classificados, 09 jun. 1987, p. 18.

5- Jornal A Notícia. Classificados, 01 nov. 1987, s.p.

6- Jornal A Notícia. Classificados, 22 fev. 1989, s.p.

$2(*)$ e $6(*)$ - Esses dois são os que ocupam por mais tempo as páginas dos Classificados do Jornal A Notícia, sendo que as respectivas figuras $2(*)$ e $6\left(^{*}\right)$ correspondem à primeira vez em que eles anunciam. Essa oferta se apresenta até o momento em que o Jornal passa por uma revisão editorial e assume o formato tabloide, em setembro de 2006, quando é adquirido pelo grupo RBS. 
Retomando a ideia da influência da mídia na oferta e visibilidade dessas religiosidades a Figura 02 reproduz uma página de classificados do Jornal A Notícia, de 26 de abril de 1987. Esse ano parece ter uma aura diferencia dos demais em termos de divulgação das religiões esotéricas e afro-brasileira. Esta situação se complementa ao analisarmos a Figura 03, com a reportagem de divulgação das telenovelas Madala e Carmem, citando Dias Gomes (autor da telenovela global) o artigo argumenta: “-O povo brasileiro, sem dúvida, é místico (...) Talvez por desesperança, por sofrimento e decepções, precisa acreditar em alguma coisa. Por isso é um povo que não tem apenas uma religião. A gente vê católico que vai à macumba, marxistas que acreditam em gurus, materialistas que fazem mapa astral. É um povo ecumênico." 10

Figura 02 - Página de anúncios de serviços espirituais em classificado.

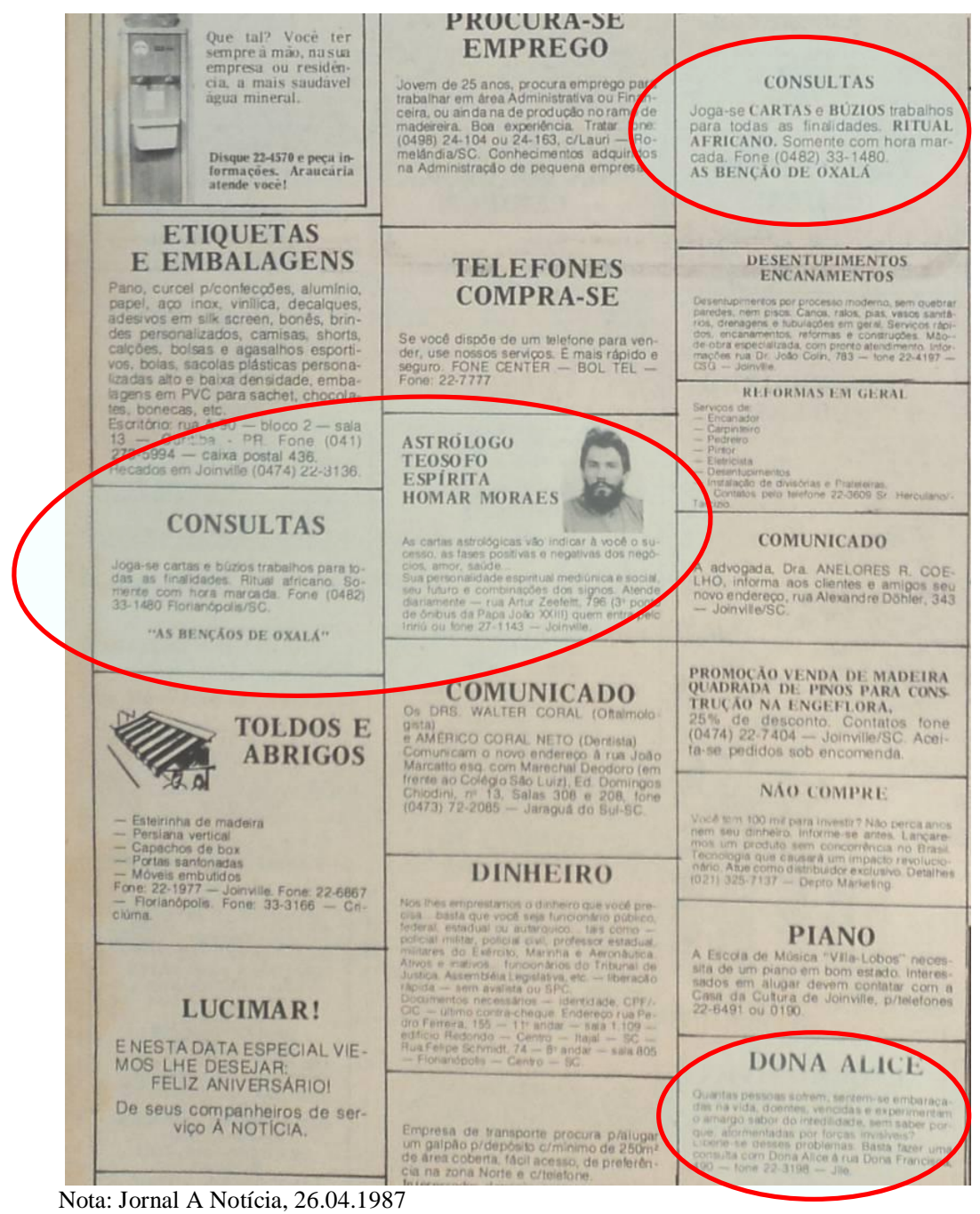

10 A NOTÍCIA, 1987, s.p.. 


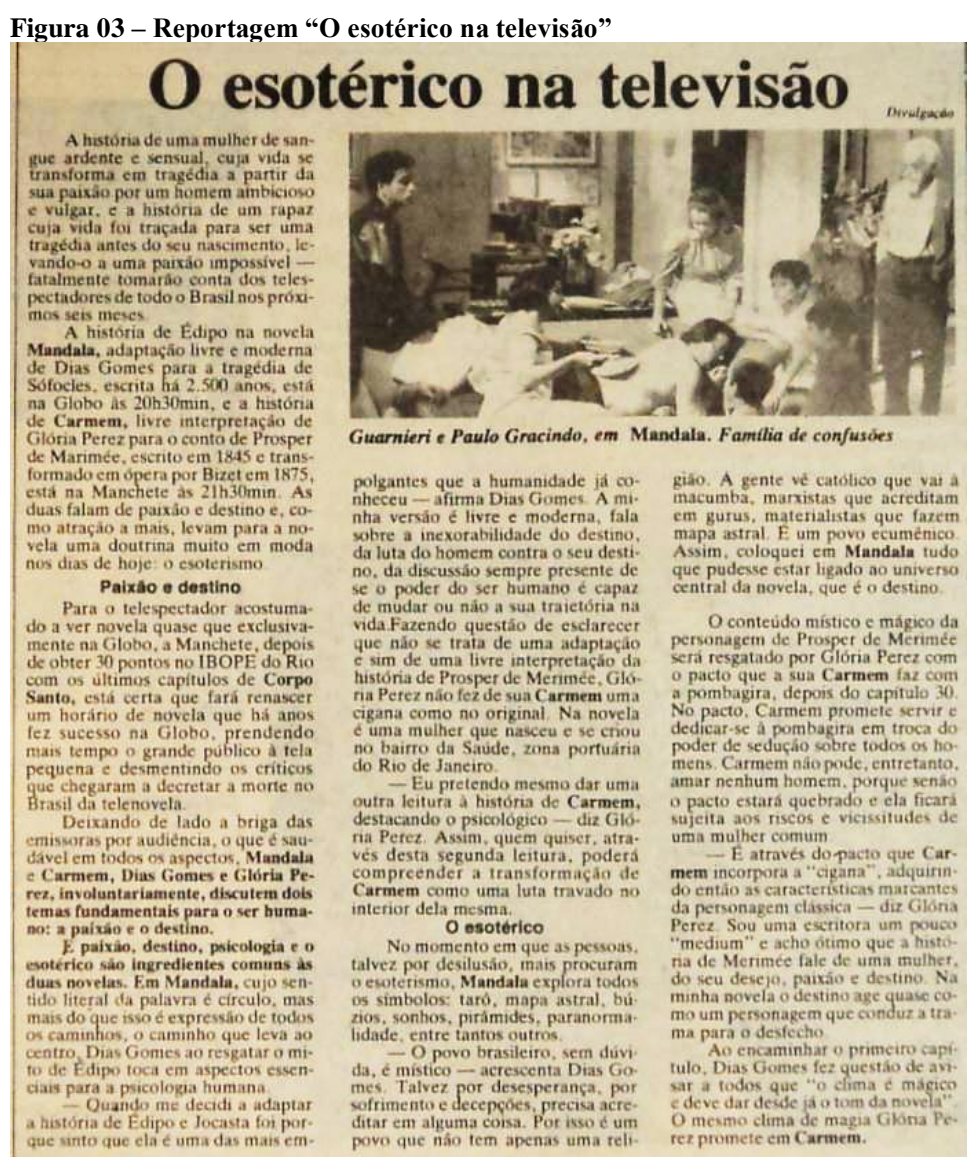

Notas: 1- Jornal A Notícia. Serviço, 03 nov. 1987; 2- destaque para o esoterismo presente no cotidiano (1987) com ressonância nas produções televisivas

\section{Umbanda e Candomblé nas brechas do mercado religioso}

A análise da documentação impressa divulgada no jornal diário de Joinville, A Notícia, no período das décadas de 1980 a 2000, revela uma intensa presença da Umbanda no campo religioso afro-brasileiro da cidade. Marcadamente, determinadas datas como é o caso do réveillon e dos dias dedicados aos santos católicos sincretizados com as entidades umbandísticas, notadamente o dia 23 de abril, em que se comemora o dia de São Jorge, santo popular da Igreja Católica, o qual é sincretizado com Ogum da Umbanda, se apresentam com certa frequências nos anos de 1980 e 1990. Desta forma, as festas de virada de ano sempre renderam reportagens voltadas às questões umbandísticas, vinculando em muitos casos, o quanto isso se reflete no comércio de artigo religiosos, inclusive, como bem demonstra a reportagem do dia 01 de janeiro de 1982 (Figura 04). Esta menciona alguns aspectos importantes, como por exemplo a existência de "mais de 100 terreiros e congares" na cidade. 
Figura 04 - Reportagem Festa de lemanjá

Sexta-feira, 1 de janeiro de 1982

\section{Festa de Iemanjá:}

lojas vendem bem

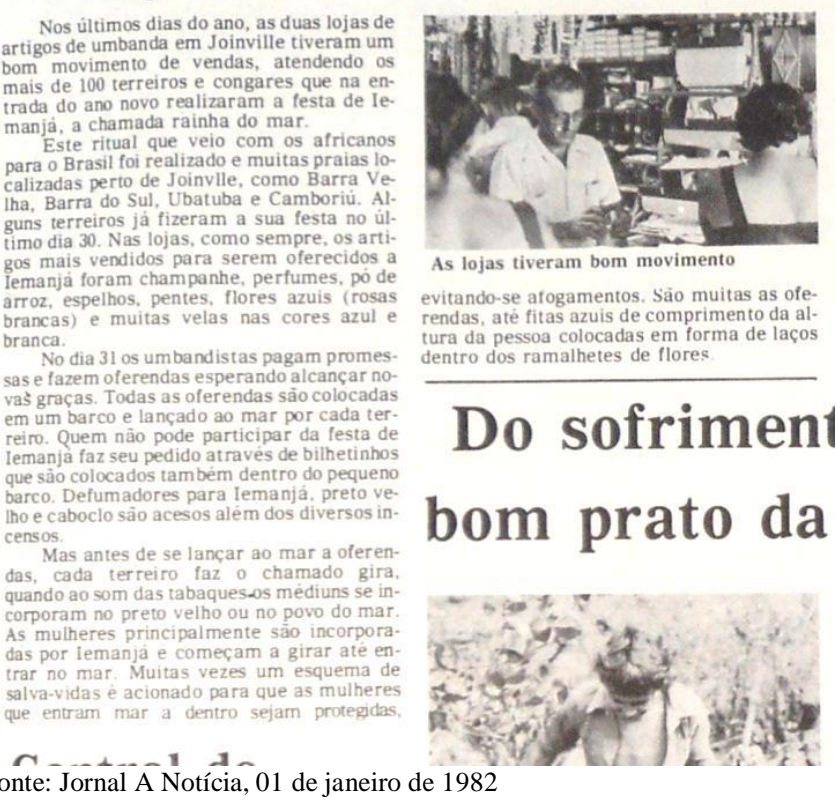

Fonte: Jornal A Notícia, 01 de janeiro de 1982

A reportagem informa alguns aspectos históricos de tal ritual afirmando que o mesmo "que veio com os africanos para o Brasil foi realizado em muitas praias localizadas perto de Joinville, como Barra Velha, Barra do Sul, Ubatuba e Camboriú." Informa, também, as dádivas oferecidas pelos devotos "champanhe, perfumes, pó de arroz, espelhos, pentes, flores azuis (rosas brancas) e muitas velas nas cores azul e branca", produtos abastecidos principalmente pelos comércios situados em Joinville. A reportagem descreve alguns aspectos do funcionamento do ritual "todas as oferendas são colocadas em um barco e lançado ao mar por cada terreiro (...) defumadores para Iemanjá, preto-velho e caboclo são acesos além dos diversos incensos (...) ao som das tabaques os médiuns se incorporam no preto velho ou no povo do mar(...) Muitas vezes um esquema de salva-vidas é acionado para que as mulheres que entram mar a dentro sejam protegidas evitando-se afogamentos."

Essa paisagem longe de ser um dado pitoresco de uma cidade voltada ao trabalho que em determinadas épocas do ano vê seus habitantes exercitando a fé em outros locais, se consolida como um lugar comum, já que os umbandistas tomam a cidade para se reunirem, celebrarem e se organizarem em movimentos. Dois eventos são 
paradigmáticos para entendermos o processo de estabelecimento das religiões afrobrasileiras em Joinville. O primeiro evento que destaco foi o anunciado Congresso Nacional de Umbanda, que foi realizado entre 12 e 13 de setembro de 1981, conforme Jornal A Notícia de 06 de junho do mesmo ano (Figura 05). Todavia, o evento foi realizado nos dias 20 e 21 de setembro e foi promovido pela União Joinvilense de Umbanda e contou com a presença de mais de 3.000 pessoas, com destaques para políticos e autoridades diversas, de vários estados brasileiros (Figura 06).

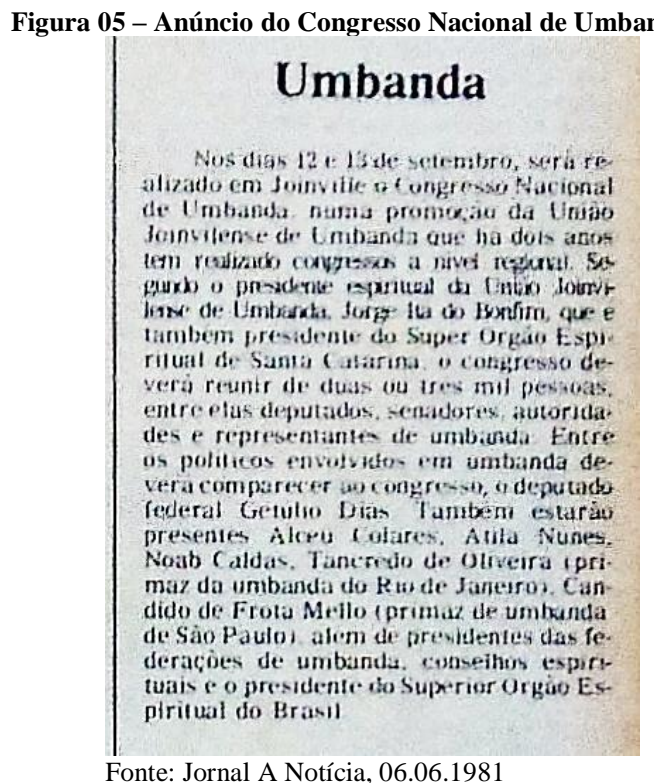

Figura 06 - Relato do Congresso Regional de Umbanda

\section{Reunião de umbandistas}

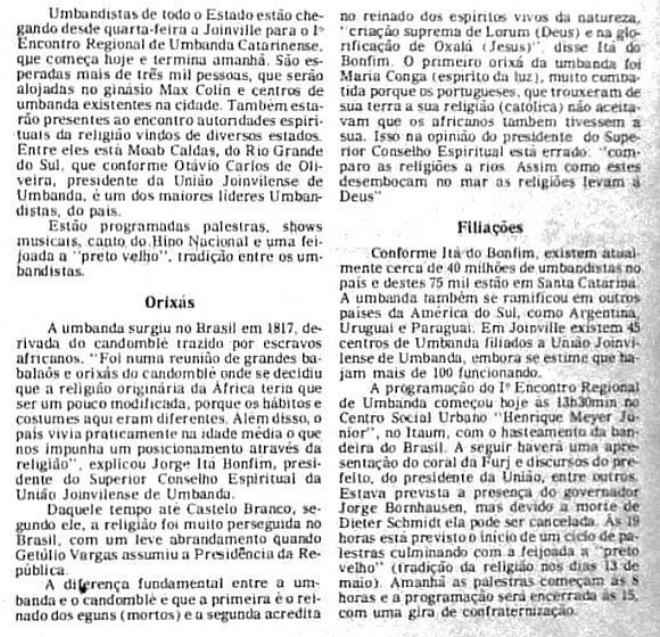

Fonte: Jornal A Notícia, 26.09.1981 
Outro evento importante para a discussão ocorreu cerca de 6 anos depois, promovido por outra associação. Assim, na tarde de 21 de abril de 1987 cerca de 350 médiuns de todo o estado de Santa Catarina reuniram-se no ginásio de esportes Abel Schultz, no centro de Joinville, assistidos por mais de 1.200 pessoas, contanto inclusive com a presença de autoridades diversas (Figura 07). O evento teve como objetivo "mostrar ao povo que a umbanda, acima de tudo, está unida, e também louvar os santos do Candomblé”, nas palavras de Omar Moraes, então, presidente da Associação Espírita de Santa Catarina. Certamente Omar estava valorizando a papel da Umbanda na sociedade ao mesmo tempo em que reconhecia em seu discurso a presença do Candomblé no campo religioso afro-brasileiro de Joinville e do Estado de Santa Catarina. A respeito desse processo de diversificação, Pai Fernando de Oxóssi, quando da realização de entrevista, comentou sobre o estranhamento causado na comunidade religiosa afro-brasileira quando da implantação do Candomblé em Joinville, em função dos rituais de iniciação, especialmente, a raspagem das cabeças:

O umbandista se sente um pouco inferior e quer passar por cima do candomblecista e este quer passar por cima do umbandista e ficam aquelas briguinhas e picuinhas das situações. Assim as diferenças se mostraram: pois um não recebe o caboclo e não recebe o Ogum enquanto para o outro a Iemanjá só poderia se manifestar em cabeça de raspado e não desceria na cabeça de umbandistas. Nem todas as pessoas naquela época aceitavam o Candomblé por que tinha que raspar a cabeça. ${ }^{11}$

Figura 07 - Capa do Jornal A Notícia anunciando a realização do $1^{\circ}$ Congresso de Umbanda da Federação Espírita de Santa Catarina

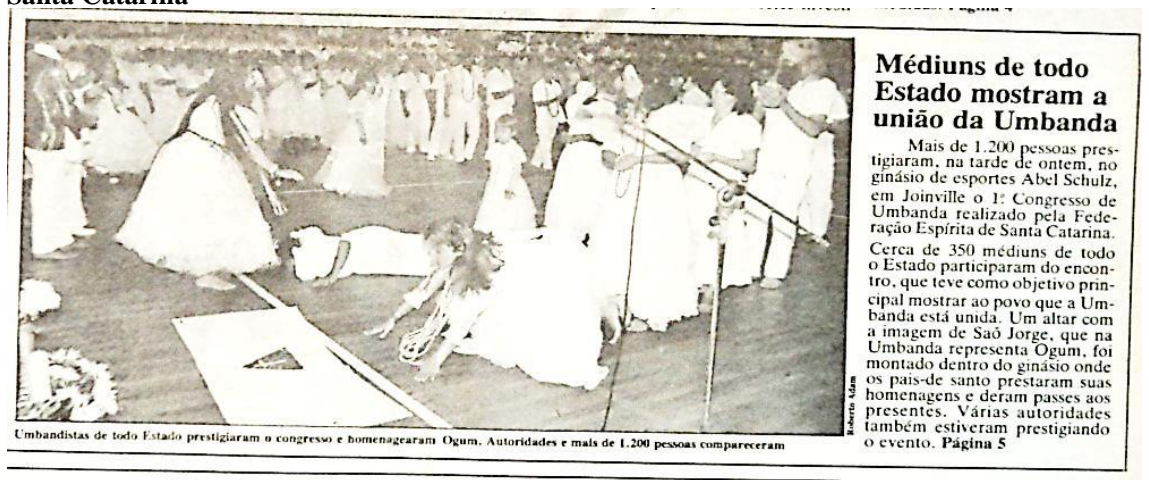

Fonte: Jornal A Notícia, 21.04.1987

${ }^{11}$ BARTEL, 2011 
Essa disputa se evidencia em matérias jornalísticas como a que foi publicada no Jornal A Notícia do dia 16 de agosto de 1987, em que numa entrevista da Ialorixá paranaense Maria Rosa de Ogum, explicava algumas questões relativas ao Candomblé e seus orixás. Em determinado ponto da entrevista ela lança um certo desafio, e diz que para derrubá-la "é preciso um prédio de um metro e setenta centímetros de altura e como ainda não tem, não há quem me derrube". ${ }^{12}$

A existência de religiões afro-brasileiras implica na configuração de um mercado que abastece os rituais dos materiais necessários ao seu bom desenvolvimento, como: sementes, preparados, contas, guias, amuletos, utensílios, domésticos, produtos alimentícios, armarinhos, animais, velas, incensos, entre outros. Zeny Rosendahl nos alerta que: "ao reconhecer que existe mais simbolismo nos objetos e coisas do que sua aparência indica, por vezes camuflado ou escondido, é sugerido afirmar que os bens simbólicos são mercadorias que possuem valor de uso e que em determinado contexto cultural passam a ter associado o valor simbólico. A natureza do bem simbólico reflete assim duas realidades, a mercadoria e o significado, o valor cultural e o valor mercantil do bem." 13

Dessa forma diversos lugares da cidade de Joinville comercializam bens indispensáveis para o exercício do culto às divindades afro-brasileiras. Atualmente, cerca de três lojas situam-se no centro da cidade e é em torno delas que as notícias, fuxicos e indicações de trabalhos giram, tanto para o povo-de-santo quanto para os usuários de serviços espirituais que não possuem muito vínculo com a religião. Essas lojas são espaços interessantes, também, em função de suas localizações: uma delas encontra-se instalada juntamente com uma Igreja Universal do Reino de Deus num prédio tombado pelo Patrimônio Histórico de Joinville; denominada de Casa das Estatuetas. Outra, a Casa das Ervas, nas imediações da praça central, também próxima a uma igreja evangélica; e outra numa das esquinas mais movimentadas da cidade; a Casa Yemanjá. Juntas oferecem uma variada gama de produtos (poções, preparados, banhos, alimentos, incensos, sementes (obi, orogbo),etc.), artefatos (ferramentas de orixás, estatuárias variadas, indumentárias, fios-de-contas, etc.), plantas, bem como, informações variadas em diversas mídias como: cds, dvds, livros, etc.. “As lojas

${ }^{12}$ Jornal A Notícia, 1987, p. local 5

${ }^{13}$ ROSENDAHL, 2005, p. 12.929. 
representam, nesse sentido, uma intermediação entre a natureza e a cidade num nível onde prevalece a cidade, pois sem sair dela é possível obter (...) artigos religiosos (...) industrializados ou coletados na natureza como folhas, pedras (otás), penas, sementes, etc. para serem consagrados nos terreiros. A loja é mesmo o "mato" ou a "reserva natural instituída" na cidade para o culto dos deuses."14

O mercado é o espaço de uma das energias mais importante das religiões afrobrasileiras que é conhecida como Exu. Ele é o dono do mercado, e recebe o título de Olóojà, que significa exatamente "o dono do mercado". Portanto, "dinheiro e mercadorias; narrativas, informações e cumprimentos têm em comum o fato de serem coisas trocadas (...) e porque a troca é movimento e o movimento implica transitividade, todas elas estão subordinadas a Èsù, o grande princípio dinâmico na cosmovisão do Candomblé." 15 Acredita-se que sem mercado não há culto e sem os cultuadores de Exu não há mercado. O mercado é, portanto, uma configuração de lugares, produtos, pessoas e energias ${ }^{16}$. Na Salvador dos anos 1930 "Os mercados eram ponto de encontro para o povo-de-santo, local de trabalho para comerciantes que, se não pertenciam ao culto, precisavam compreender a sua lógica para atender e atrair clientes" ${ }^{17}$, como bem aponta Iris Verena de Oliveira. O Mercado Público Municipal e as lojas de produto votivos, armarinhos, aviários, etc., espalhadas por Joinville, dos anos 1980 em diante passou a receber a demanda do povo dos Ilês Axé de Candomblé que se instalaram na cidade, desde então. Nesse sentido a cidade e seus comerciantes precisaram adaptar sua linguagem e seu atendimento a esse público que muito consome e necessita estar conectado aos outros centros do país, pois, "quem quer que pretenda se qualificar como fornecedor deve, antes de tudo, qualificar-se como conhecedor (...) com o seu prestígio, cresce a sua freguesia"18. Atualmente, inclusive as lojas devem praticar preços condizentes com o mercado nacional em virtude da facilidade de acesso ao comércio de capitais como São Paulo e Rio de Janeiro que atende a todo o território nacional, via internet, telefone e envio via serviços postais.

Ogã Maurício, um de nossos entrevistados mais eloquentes foi testemunha do processo de estabelecimento do mercado de produtos para abastecer as casas de culto de

\footnotetext{
${ }^{14}$ SILVA, 1995, p. 215.

15 VOGEL, 1998, p. 7

${ }^{16}$ Para uma etnografia do mercado fornecedor dos produtos de consumo dos ilês axés de Candomblé conferir VOGEL, Op. Cit.., p.p. 08-15.

${ }^{17}$ OLIVEIRA, 2011, p. 10

18 VOGEL, Idem., p.09.
} 
Candomblé em Joinville. Ele lembra da dificuldade que era encontrar, na cidade, determinados elementos fundamentais ao culto. $\mathrm{O}$ acesso aos mesmos era:

\begin{abstract}
Muito precário, por que não existia, existia uma Casa das Ervas assim como a do Emilson ${ }^{19}$. Para o senhor ter uma ideia, praticamente, a casa do Emilson eu vi nascer, inclusive, eu fazia alguns produtos. Curitiba era o ponto mais próximo para se conseguir alguma coisa, $\mathrm{obi}^{20}$, orobô ${ }^{21}$, búzios, e essas coisas todas. Como eu viajava e ia sempre para o nordeste, trazia de lá e como trazia para o Emilson latas de 18 quilos de dendêt ${ }^{22}$, sacos de 30, 40, quilos de búzios, assim, praticamente de graça, eu conseguia lá. E conseguia absolutamente tudo, até folhas de Irôco ${ }^{23}$, folhas de qualquer coisa, eu levava relacionado e se eu achasse trazia, se eu não achasse fazia o que? Paciência. ${ }^{24}$
\end{abstract}

O mercado de produtos dedicados ao culto aos orixás e entidades em Joinville está em franca expansão. Na região central da cidade contabilizamos a existência de três lojas as quais suprem boa parte das necessidades dos rituais de orixás, inkisses e entidades da cidade e região (Figura 08). O fornecimento local desse produtos ainda carece de variedade e constância de produtos. Assim, devido à localização estratégica da cidade em relação aos grandes centros fornecedores boa parte desses produtos chegam aos terreiros da cidade por diversos meios.

Atualmente, aproveitando-se das brechas do mercado deixado pelas lojas especializadas as quais, ainda hoje, não suprem adequadamente o exigente mercado do Candomblé joinvilense, muitos comerciantes ambulantes internacionais trazem para a cidade produtos africanos como sementes, sabões, indumentárias, tecidos, fios de conta, que se destacam em relação aos produtos nacionais, em função de sua exclusividade e do senso estético aplicado nesses objetos, como é o caso de uma família de nigerianos, sediada em Curitiba/PR que atende, além do mercado paranaense, o catarinense, com visitas sistemáticas aos ilês axés, terreiros e residências(Figura 09).

\footnotetext{
${ }^{19}$ Refere-se à Casa das Ervas, comércio que oferece boa parte dos elementos necessários ao desenvolvimento do Candomblé.

${ }^{20}$ Cola acuminata

${ }^{21}$ Garcinia kola

${ }^{22}$ Elaeis guineensis

${ }^{23}$ Chlorophora excelsa

${ }^{24}$ SANTOS, 2009.
} 
Figura 08 - Comércio de artigos votivos, Casa das Ervas

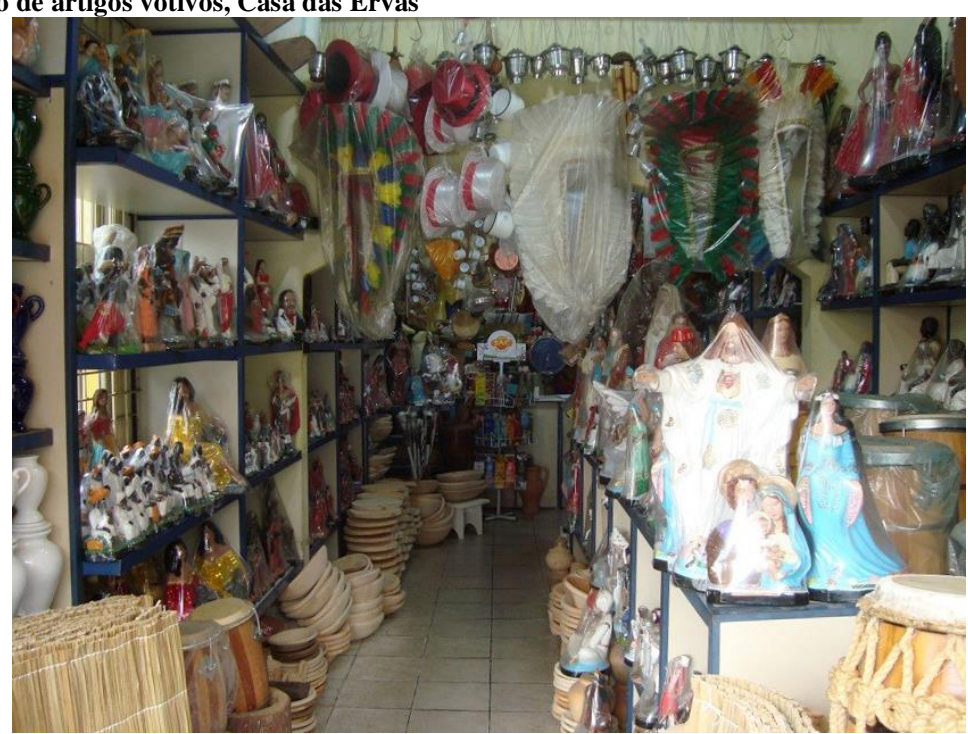

Autor: Gerson Machado, 29.10. 2012

Figura 09 - Comércio de produtos feitos por Nigerianos, de porta em porta.

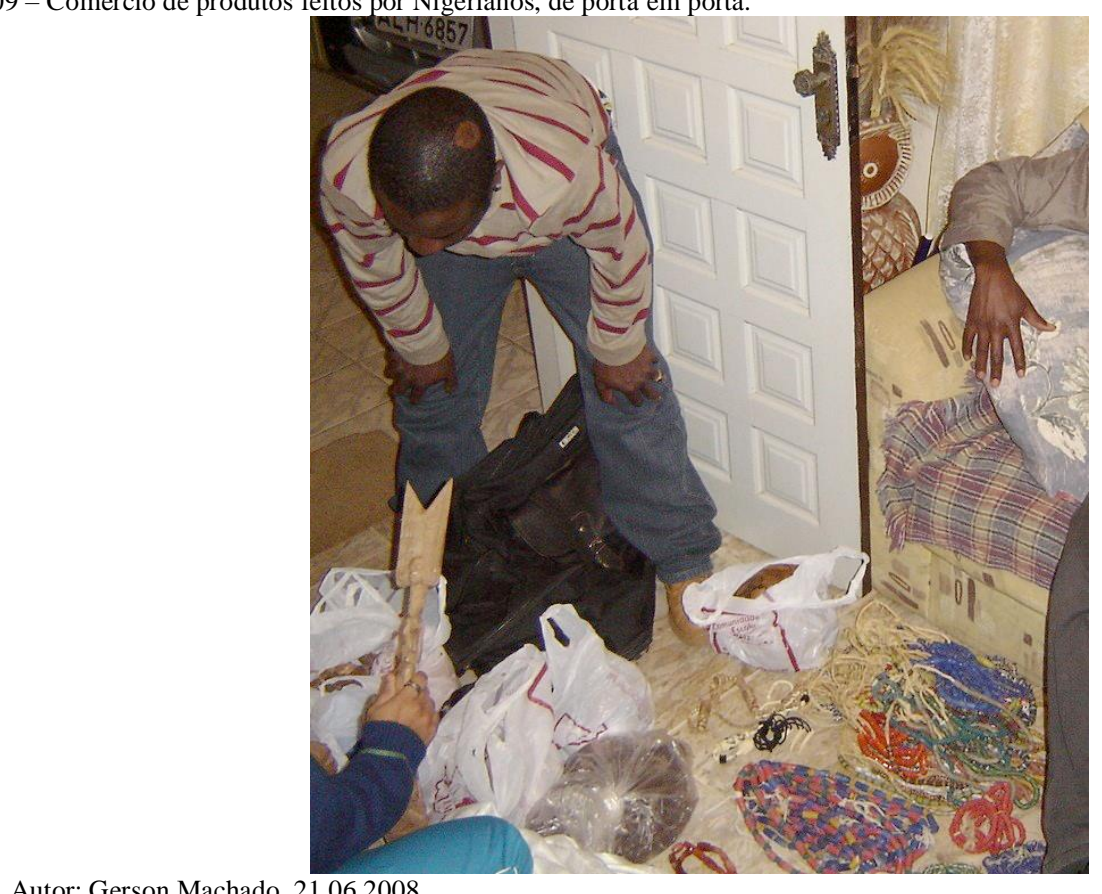

Autor: Gerson Machado, 21.06.2008.

Além de conectar Joinville aos centros de distribuição de produtos, em virtude de seu ofício de motorista rodoviário, Ogã Maurício foi se inteirando a respeito da produção de ferramentas de orixás. Sua arguta observação desses elementos fora da cidade permitiu se firmar no mercado local como o principal fornecedor de ferramentas dos orixás. Ressalto que a produção das "ferramentas" ou "ferros" dos orixás envolvem um domínio de técnicas de manejo de materiais e equipamentos diversos, além do domínio da iconografia que materializa a narrativa e os "fundamentos" dos orixás. É um 
exercício de produção de Arte-sacra, vinculada à religiosidade afro-brasileira, com exemplares que apresentam apurado senso estético. "São ferros de assentamentos, azés ou filás em palha-da-costa, diloguns em miçangas, adês em latão dourado recortado e marchetado, alfanjes em cobre, correntes de ibá em ferro cromado, panos-da-costa em richelieu, abebês em flandres e adornados de búzios e guizos, mariôs em folha de dendezeiro desfiada, sem falar na culinária, área tão digna, complexa e fundamental à memória ancestre dos deuses e seus vínculos com os homens." ${ }^{25}$ Os centros mais tradicionais de difusão dessas religiões são os que concentram a produção, em maior vulto, desses objetos de culto, abastecendo os mercados dos centros menos tradicionais onde essa religião se manifesta. Nessa condição, Joinville importou, durante muito tempo, esses materiais.

Hoje, Ogã Maurício é uma referência à todo o povo-de-santo da cidade quando há necessidade desses objetos. Raul Lody explica que "o domínio na construção de objetos - notadamente os de destinação ritual religiosa - assimila saberes sobre história religiosa, liturgia e função específica para o desempenho em âmbito sagrado; são saberes arcaicos ora preservados, ora atualizados para cada situação, região, local e usuário específico."26 Boa parte dos rendimentos que dão sustento ao seu núcleo familiar provém da produção desses objetos sacros. Assim, o saber envolvido nessa produção é repassado continuamente ao seu filho que ajuda-o na oficina e, também, produz boa parte desses materiais para o mercado religioso afro-brasileiro de Joinville. Essa circularidade de saberes é comum nesse universo "Os conhecimentos tecnológicos e a pedagogia da arte/artesanato voltados à produção e consumo afro-brasileiro vêm naturalmente na transmissão de conhecimentos por laços familiares, por adestramento de aprendizes em oficinas e, em muitos casos, no desempenho sacerdotal - tecnologia do sagrado -, ou em momentos iniciáticos em terreiros, quando o noviço desenvolve trabalhos complementares aos símbolos e ferramentas dos deuses." 27.

Sobretudo o mercado de produtos e saberes em torno do Candomblé não pode ser monopolizado nem por pessoa, muito menos por grupo. É necessário a constituição de redes de solidariedades que interdependentemente alimentam-se e atualizam-se, continuamente, a partir da circulação de saberes e valores. Pai Nino de Ogum comentou

\footnotetext{
${ }^{25}$ LODY, 2003,p. 18.

${ }^{26}$ LODY, Op. Cit., p. 18

${ }^{27}$ LODY, Idem, p. 18-19
} 
que para se fazer santo no Candomblé existem folhas que aqui para nós é muito difícil de serem encontradas. Então, ou se busca em Curitiba ou minha família de santo manda de São Paulo para cá! A nossa flora aqui é muito rica, porém, não são as folhas de axé! E quando você acha alguma coisa por aqui você tenta cultivar para poder ter. ${ }^{28}$

O Ogã Maurício, por exemplo, em toda a sua trajetória reconhece a presença e a importância das redes de relações o que explicou, inclusive, sua atuação como artista sacro.

É como eu disse pro senhor, as coisas acontecem na vida da gente quando menos se espera! Eu realmente eu não sabia que eu tinha esse dom de fazer ferramentas, de confeccionar essas coisas, não sabia não, e estou engatinhando ainda, nesse tipo de confecção, mas isso apareceu assim por acaso. Por causa de quem? Por causa de meu compadre Mucongo, e foram as primeiras ferramentas que eu pude confeccionar, foi lá para a casa de Iaiá ${ }^{29}$, foi o que? Alguns colarezinhos feitos de latão, que até hoje soa no meu ouvido ela mesmo dizer que foi uma joia. Foram feitos de latão bem polido, ficaram parecidos com ouro. (...) depois disso aí eu fui distribuindo para o Emilson e depois dele foi passando para outras casas de Umbanda, inclusive para algumas cidades adjacentes. Tenho muita procura, muita procura mesmo. Eu até parei de atender essa procura aqui em casa (...) eu prefiro fazer para o Emilson lá da Casa das Ervas, por que ele me pede uma ferramenta e eu faço cinco e ele fica com todas. Então eu firmei um contrato com ele lá, uma coisa assim mais séria, mais profissional, pelo circulo de amizade, pelo tempo de amizade que nos temos, para eu confeccionar ferramentas somente pra ele, somente pra loja. ${ }^{30}$

Outro saber aplicado ao culto dos orixás é o que envolve a produção das indumentárias tanto as de uso cotidiano quanto as de uso ritual, inclusive as utilizadas pelos orixás em transe, em sua performance pública. São tecidos, cores, laços, adornos que conferem ao fiel e ao orixá manifestado a inserção numa teia de significados que informam o lugar hierárquico e sagrado que cada um ocupa. A confecção depende de um domínio técnico e da interação entre o que solicita o serviço e pessoa que confecciona. É um campo de relações demarcado, que implica um processo de referenciação e cumplicidade. O neófito para adentrar nesse universo precisa aprender a contratar os serviços e a dominar o mercado e os códigos. Essa aprendizagem se dá, especialmente, através da vivência no espaço sagrado condensado nos ilês axés mas, também, através das autoridades sacerdotais (iyalorixás, babalaorixas, egbomis, ogãs,

\footnotetext{
${ }^{28}$ CUNHA, 2011.

${ }^{29}$ Iaia é como este entrevistado se refere à Iyalorixá Jacila de Oxum.

${ }^{30}$ SANTOS, Op. Cit..
} 
ekedes, entre outros) que apresentam aos "mais novos" o sistema de significados que circunda os Candomblés.

\section{Considerações Finais}

Então me diz qual é a graça,

De já saber o fim da estrada,

Quando se parte rumo ao nada?

(Paulinho Mosca, A Seta e o Alvo)

A epígrafe acima é bastante elucidativa, já que ela sintetiza, do meu ponto de vista, o desejo de boa parte da historiografia contemporânea que adota uma discussão aberta com o fenômeno da cultura, com enfoque específico a uma de suas dimensões que é a religião e a religiosidade humana.

Justamente a religião que, na tradição da historiografia, vinha sendo pouco considerada em detrimento de outros temas "mais nobres" de investigação, como a economia, a política, os movimentos sociais, as biografias, dentre outros. Quando ela ocupava o cenário de análise, por vezes, foi “... explicada de fora de si mesma. Parte-se da premissa, racionalista e ilustrada, de que a religião, por si mesma, é ilusão, ideologia, conceito inadequado, enfermidade, falsa consciência" ${ }^{31}$. Longe de querer conduzir essa experiência de constituição de uma religião e seus discursos ao "tribunal da ciência, da razão (ou da genealogia da vontade de poder), com o objetivo de ser examinada, interrogada, experimentada e questionada" ${ }^{32}$, o que me propus nesta pesquisa foi, humildemente, me aproximar, com um pé, do “jogo linguístico” próprio do Candomblé, e com o outro, apoiar-me nas interpretações já feitas sobre este fenômeno para outros locais do país, sem a pretensão de esgotar quaisquer dos pontos de apoio utilizados.

Minha proposta foi, à maneira dos instantâneos fotográficos, "capturar" determinados movimentos e dar a eles uma narrativa sobre o ponto de vista da historiografia. Nas palavras de Clifford Geertz "o etnógrafo "inscreve" o discurso social: ele o anota. Ao fazê-lo, ele o transforma de acontecimento passado, que existe apenas em seu próprio momento de ocorrência, em um relato, que existe em sua inscrição e que pode ser consultado novamente" 33 .

\footnotetext{
${ }^{31}$ TRÍAS, 2000, p. 113. (destaques no original)

32 TRIAS, Op. Cit., p. 113. (destaques no original

${ }^{33}$ GEERTZ, 1989., p. 29
} 
Nesta perspectiva, concordo com Aldo Gargani quando ele propõe uma saída para a sinuca conceitual que sempre colocou a religião ou entre a interpretação metafísica exegética ou a racional científica, afirmando que: "é nessa capacidade interpretativa dos movimentos da existência em que estamos mergulhados, e não na predisposição a atrair e tragar os processos da vida e da história num outro domínio ontológico de entidades transcendentes, que é possível colher, hoje, o vértice mais apropriado para repensar filosoficamente a experiência religiosa". ${ }^{34}$

Interpretação é o conceito chave deste trabalho que teve na cultura sua mais inquietante provocação. A interpretação é feita a partir do fluxo do discurso social e tenta salvar os enunciados da sua possibilidade de extinção, fixando-o em formas que possibilitem um acesso posterior. É condição fundamental para se entender os fenômenos culturais, pois, como explicou Clifford Geertz, ela “...pode ser entendida como um conjunto de textos, eles mesmos conjuntos, que o antropólogo tenta ler por sobre os ombros daqueles a quem eles pertencem". ${ }^{35}$

É preciso ressaltar que, como discurso, as religiões também são inundadas pelos fluídos da atual configuração da modernidade, porém o discurso que se pretende duro e monolítico das religiões de uma maneira geral propicia aos sujeitos, dispersos e flutuantes, "lançar âncoras" e se fixar nesses blocos/lugares para compor e recompor novas e cambiantes identidades. Isso não garante, entretanto, que a corda da âncora não se rompa deixando-os à deriva, indefinidamente, ou que a própria âncora perca sua fixação e busque novos pontos de apoio, ou ainda que elas mesmas se dissolvam. Essa metáfora talvez nos ajude a compreender a fluidez das identidades religiosas neste nosso tempo. Portanto, quanto mais as religiões conseguirem manter uma aparência de solidez e perenidade, mais poderão se oferecer num mercado de bens simbólicos a ser consumidos pelos indivíduos. Numa época em que, como diz Sueli Rolnik, estamos cada vez mais viciados em consumir identidades, as religiões são mais um item das prateleiras desse tipo de mercado. ${ }^{36}$

Em relação ao Candomblé especificamente, é interessante notar que, como uma religião liquescente, conforme afirma Antonio Pierucci ${ }^{37}$, entendi que ela pode ser comparada também a um objeto flutuante que atende a todos os tipos de indivíduos,

\footnotetext{
${ }^{34}$ GARGANI, 2000, p. 129.

${ }^{35}$ GEERTZ, 1989, p. 212.

36 ROLNICK, 1997.

${ }^{37}$ PIERUCCI, 2006.
} 
diluídos como estão nos processos atuais. Não mais uma religião enraizada, fato social contra a anomia tão temida pelos sociólogos ligados à tradição durkheiminiana, mas sim desenraizada, sectária, dinâmica, inspirando-me nas discussões de Max Weber. O Candomblé, como bem lembra Pierucci, deixa de ser uma religião étnica voltada à coesão grupal para se tornar uma religião universal dirigida aos indivíduos dispersos. Dessa universalização alcançada pelo Candomblé provém, também, sua expansão para terras que se acreditavam pouco férteis para esse tipo de experiências, como é o caso de Joinville. Aparentemente, as tramas de linguagem que constituem uma narrativa para essa cidade não dão margens à expressão de manifestações identitárias aliadas à cultura afro-brasileira. Pretende-se que Joinville seja loura, branca e de olhos azuis.

Todavia, esse artifício narrativo não se sustenta se voltarmos nossos olhos com um pouco mais de atenção para além daquilo que os outdoors nos apresentam. As lembranças dos nossos entrevistados, além das outras tipologias de fontes, expõem uma realidade muito mais multifacetada, policromática e polifônica. Tanto os entrevistados, membros de religiões de matriz africana, quanto a própria cidade, por intermédio de seus periódicos, anunciam uma complexa teia de relações.

Por fim, vale ressaltar que Joinville também contribui com o processo de heterogeneização da sociedade brasileira, tanto pelo seu celebrado processo de imigração europeu, quanto pelos outros processos que trouxeram para a cidade uma diversidade pulsante de vida e sistemas culturais.

\section{Referenciais}

A NOTÍCIA. 30 Ago. 1980, p.17. (Classificados)

A NOTÍCIA. 06 Jan. 1981.

A NOTÍCIA. 26 Set. 1981.

A NOTÍCIA. 01 Jan. 1982.

A NOTÍCIA. 06 Dez. 1985, p.16. (Classificados)

A NOTÍCIA. 21 Abr. 1987.

A NOTÍCIA. 09 Jun. 1987, p. 18. (Classificados)

A NOTÍCIA. 02 Set. 1987, p. 18. (Classificados)

A NOTÍCIA. 01 Nov. 1987, s.p.. (Classificados) 
A NOTÍCIA. 03 Nov. 1987, s.p..

A NOTÍCIA. 22 Fev. 1989, s.p.. (Classificados)

BARTEL, Fernando Sebastião Entrevista. Joinville: 13 Abr. 2011.

CUNHA, Orlando. Entrevista. Joinville: 24 Mar. 2011.

DERRIDA, Jacques. Fé e saber. In:VATTIMO, Gianni; DERRIDA, Jacques (orgs.). A religião: o seminário de capri. São Paulo: Estação Liberdade, 2000, p.p. 11-89.

FONTOURA, Arselle de Andrade da; SILVA, Janine Gomes da. Histórias sobre a presença negra em Joinville no século XIX. Joinville Ontem \& Hoje. Março, 2005, p.22-25.

GARGANI, Aldo. A experiência religiosa como evento e interpretação. In: DERRIDA, Jacques e VATTIMO, Gianni. A Religião. São Paulo: Estação Liberdade, 2000, p.p.125-150.

GEERTZ, Clifford. Um jogo absorvente: notas sobre a briga de galos balinesa. In: A interpretação das culturas. Rio de Janeiro: LTC - Livros Técnicos e Científicos Editora S.A., 1989, p.p. 185-213.

GEERTZ, Clifford. Uma descrição densa: por uma teoria interpretativa da cultura. In: A interpretação das culturas. Rio de Janeiro: Zahar, 1978, p.p. 13-41.

GRUNER, Clóvis. Leituras Matutinas; utopias e heterotopias da modernidade na imprensa joinvilense. Curitiba: Aos Quatro Ventos, 2003.

GUERREIRO, Silas. “Quer ver o seu futuro, seu moço?” Uma interpretação dos jogos divinatórios na sociedade contemporânea. In: ISAIA, Artur Cesar (org.) Crenças, sacralidades e religiosidades. Florianópolis: Insular, 2009, p. 249-265.

LODY, Raul. Dicionário de arte sacra \& técnicas afro-brasileiras. Rio de Janeiro: Pallas, 2003.

MACHADO, Gerson. Memórias e relações interétnicas: conflitos e acomodações numa comunidade rural catarinense. 1.ed.. Itajaí: Casa Aberta, 2015.

OLIVEIRA, Iris Verena Santos de. Cartografias simbólicas de Salvador: Espaços sacralizados pelo povo de santo. In: FERREIRA, Marieta de Morais (org.). Anais do XXVI Simpósio Nacional de História ANPUH. São Paulo: internet/ANPUH, julho 2011.

PESAVENTO, Sandra Jathay. Negros feitiços. In: ISAIA, Artur César (org.). Orixás e espíritos: o debate interdisciplinar na pesquisa contemporânea. Uberlândia: EDUFU, 2006, pp. 129-172.

PIERUCCI, Antônio Flávio. Religião como solvente: uma aula. Novos Estudos. N.75, jul. 2006, p.p. 111 $-127$.

PRANDI, Reginaldo. As religiões afro-brasileiras e seus seguidores. Civitas Revista de Ciências Sociais. V.3, n.1, Porto Alegre: PUC/RS, jun. 2003.

ROLNIK, Sueli. Toxicômanos de identidade. Subjetividade em tempo de globalização. In: LINS, Daniel (org.). Cultura esubjetividade. Saberes Nômades. Papirus, Campinas 1997; pp.19-24.

ROSENDAHL, Zeny. Território e Territorialidade: Uma Perspectiva geográfica para o estudo da religião. In: Anais do X Encontro de Geógrafos da América Latina. São Paulo: USP, 20 a 26 de março de 2005 , p.p. $12.928-12.942$.

SCHWARCZ, Lílian Moritz. O espetáculo das raças; cientistas, instituições e questão racial no Brasil. São Paulo: Companhia das Letras, 1993. 
SEYFERTH, Giralda. A colonização alemã no Vale do Itajai-Mirim. Porto Alegre: Ed. Movimento, 1974.

SILVA, Vagner Gonçalves da. Orixás da Metrópole. Petrópolis, RJ: Vozes, 1995.

TRIAS, Eugênio. Pensar a religião: o símbolo e o sagrado. In: DERRIDA, Jacques e VATTIMO, Gianni. A Religião. São Paulo: Estação Liberdade, 2000, p.p. 109- 124.

VOGEL, Arno et alli. A galinha d’Angola. 2.ed. Rio de Janeiro: Pallas, 1998.

SANTOS, Maurício Ferreira dos. Entrevista. Joinville: 20 Jun. 2009.

Recebido: 20/04/2016

Received: 04/20/2016

Aprovado: 30/05/2016

Approved: 05/30/2016 